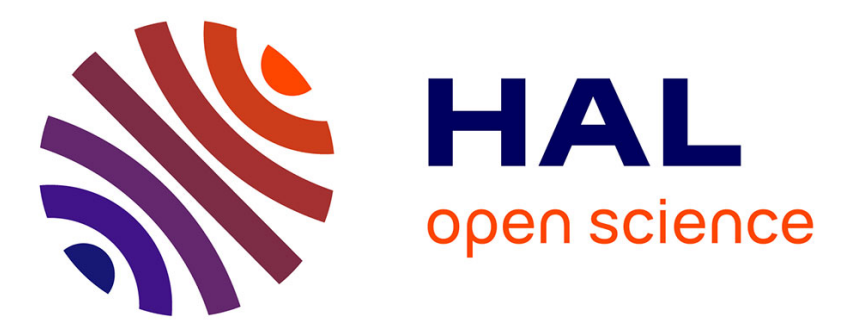

\title{
LYL1 activity is required for the maturation of newly formed blood vessels in adulthood.
}

\author{
Nelly Pirot, Virginie Deleuze, Rawan El-Hajj, Christiane Dohet, Fred
} Sablitzky, Philippe Couttet, Danièle Mathieu, Valérie Pinet

\section{- To cite this version:}

Nelly Pirot, Virginie Deleuze, Rawan El-Hajj, Christiane Dohet, Fred Sablitzky, et al.. LYL1 activity is required for the maturation of newly formed blood vessels in adulthood.. Blood, 2010, 115 (25), pp.5270-9. 10.1182/blood-2010-03-275651 . hal-03022021

\section{HAL Id: hal-03022021 \\ https://hal.science/hal-03022021}

Submitted on 13 Oct 2021

HAL is a multi-disciplinary open access archive for the deposit and dissemination of scientific research documents, whether they are published or not. The documents may come from teaching and research institutions in France or abroad, or from public or private research centers.
L'archive ouverte pluridisciplinaire HAL, est destinée au dépôt et à la diffusion de documents scientifiques de niveau recherche, publiés ou non, émanant des établissements d'enseignement et de recherche français ou étrangers, des laboratoires publics ou privés. 


\title{
LYL1 activity is required for the maturation of newly formed blood vessels in adulthood
}

\author{
Nelly Pirot, ${ }^{1-3}$ Virginie Deleuze, ${ }^{1-3}$ Rawan El-Hajj, ${ }^{1-3}$ Christiane Dohet, ${ }^{1-3}$ Fred Sablitzky, ${ }^{4}$ Philippe Couttet, ${ }^{5}$ \\ *Danièle Mathieu, ${ }^{1-3}$ and *Valérie Pinet ${ }^{1-3}$ \\ ${ }^{1}$ Institut de Génétique Moléculaire de Montpellier, Unite Mixte de Recherche 5535, Centre Nationale de la Recherche Scientifique, Montpellier, France; \\ 2Université Montpellier 2, Montpellier, France; ${ }^{2}$ Université Montpellier 1, Montpellier, France; ${ }^{4}$ Institute of Genetics, The University of Nottingham, School of \\ Biology, Queen's Medical Center, Nottingham, United Kingdom; and 5Novartis Institute for Biomedical Research (NIBR), Investigative Toxicology, Basel, \\ Switzerland
}

The 2 related basic helix loop helix genes, LYL1 and TAL-1 are active in hematopoietic and endothelial lineages. While Tal-1 is essential for both hematopoietic and vascular development, the role of $L y l 1$ appears to be distinct as deficient mice are viable and display modest hematopoietic defects. Here, we reveal a role for $L y / 1$ as a major regulator of adult neovascularization. Tumors implanted into Lyl1deficient mice showed higher proliferation and angiogenesis, as evidenced by enlarged lumens, reduced pericyte coverage and increased permeability, compared with wild type littermates. Of note, Lyl1-deficient tumor vessels exhibited an up-regulation of Tal-1, the VE-Cadherin target gene, as well as Angiopoietin-2, 3 major actors in angiogenesis. Hematopoietic reconstitution experiments demonstrated that this sustained tumor angiogenesis was of endothelial origin. Moreover, the angiogenic phenotype observed in the absence of Lyl1 function was not tumor-restricted as microvessels forming in Matrigel or originating from aortic explants were also more numerous and larger than their wild-type counterparts. Finally, LYL1 depletion in human endothelial cells revealed that LYL1 controls the expression of molecules involved in the stabilization of vascular structures. Together, our data show a role for LYL1 in the postnatal maturation of newly formed blood vessels. (Blood. 2010; 115(25):5270-5279)

\section{Introduction}

The vascular system through development and adulthood answers to injury and remodeling and is one of the key systems sustaining normal physiology. Conversely, its deregulation also underlies multiple pathologic processes such as ischemia, inflammation and tumor. Angiogenesis normally occurs as a sequential series of morphogenetic events resulting in a functional network of vessels. Regulation of endothelial cell function in all these processes requires the integration of complex signals by the coordinated action of specific transcription factors.

LYL1 is a member of the large basic helix loop helix (bHLH) family, and is closely related to TAL-1 (also called $S C L$ ). Both $L Y L 1$ and TAL-1 were identified through their involvement in chromosomal rearrangements in human T-cell leukemia (reviewed in Baer $^{1}$ ). Tal-1 deficiency causes embryonic lethality due to the absence of hematopoietic cell formation ${ }^{2-5}$ and several studies have shown that Tal-1 is also involved in the formation of the vascular system. ${ }^{6-10}$ Unlike Tal-1, Lyll is not essential for developmental processes, since homozygous disruption of Lyll activity induces only a mild hematopoietic phenotype. ${ }^{11}$ The viable Lyll-deficient mice display a reduced number of B cells and impaired long-term hematopoietic reconstitution capacity. ${ }^{11}$ The highly conserved bHLH motifs between $T A L-1$ and $L Y L 1$ are functionally interchangeable to restore immature hematopoiesis in Tal-1 deficient embryonic stem cells. ${ }^{4,12}$ Moreover, Tal-1 and Lyll display redundant activities to maintain adult hematopoietic stem cell functions. ${ }^{13}$ However, full-length LYL1 cannot rescue early lethality of em- bryos lacking Tal-1, ${ }^{4,14}$ indicating that domains other than the bHLH exert nonredundant functions. We reported that LYL1 but not TAL-1, interacts with p105-NFKappaB1, and that its ectopic expression in human Jurkat $\mathrm{T}$ cells reduces NF-KappaB1dependent transcription. ${ }^{15}$ Moreover, the N-terminal domain of LYL1, which completely differs from TAL-1, mediates functional interactions with the ubiquitous transcription factors CREB-1 and activates transcription of CREB-1 targets in human K562 erythroid cells. ${ }^{16}$

A recent study conducted in mouse embryos revealed highly overlapping expression of Lyll and Tal-1 not only in hematopoietic ontogeny but also in the developing vasculature and endocardium. ${ }^{17}$ In adults, TAL-1 expression is undetectable in quiescent endothelium, but is present in newly formed blood vessels, ${ }^{18,19}$ including vascular proliferations and tumor lymphatic vessels. ${ }^{20,21}$ We previously reported the requirement of TAL-1 for adult endothelial morphogenesis, where it activates the expression of VE-Cadherin, the major constituent of endothelial adherens junctions. ${ }^{22,23}$

The expression and the role of $L Y L 1$ in adult endothelium are still undefined. We show here that, in contrast to TAL-1, LYL1 is expressed in both angiogenic and mature adult endothelium. Loss of function reveals that $\mathrm{Lyll}$ is not required for the morphogenetic events leading to endothelial tube formation, but for the maturation and stabilization of newly formed blood vessels in adult mice. At the molecular level, we provide evidence that LYL1 controls the
Submitted March 19, 2010; accepted April 15, 2010. Prepublished online as Blood First Edition paper, April 23, 2010; DOI 10.1182/blood-2010-03-275651.

${ }^{*}$ D.M. and V.P. share senior authorship (alphabetical order).

The online version of this article contains a data supplement.
The publication costs of this article were defrayed in part by page charge payment. Therefore, and solely to indicate this fact, this article is hereby marked "advertisement" in accordance with 18 USC section 1734.

() 2010 by The American Society of Hematology 
expression of several molecules, involved in the formation and/or the tightening of endothelial adherens junctions. Together, our data suggest a model in which TAL-1 and $L Y L 1$ act in a coordinated manner in adult angiogenesis to control lumen formation and vessel maturation, respectively.

\section{Methods}

\section{Cell cultures}

Primary endothelial cells (ECs) from human umbilical vein ECs (HUVECs), obtained from Clonetics (Lonza) and the immortalized human endothelial cell line hTERT- $1^{24}$ obtained from the United States Centers for Disease Control, were cultured in complete endothelial cell growth medium-2 microvascular (Lonza) with 3\% fetal calf serum (FCS; HyClone, Perbio Science). Lewis Lung Carcinoma (LLC) cells or B16-F10 melanoma cells were cultured in Dulbecco Modified Eagle Medium containing 10\% FCS.

\section{In vitro quiescence assay}

HUVECs $\left(1 \times 10^{6}\right)$ were allowed to grow to confluence onto 60 -mm dishes in complete EGM2 medium containing the angiogenic growth factors vascular endothelial growth factor (VEGF) and basic fibroblast growth factor (bFGF). After 48 hours, medium was replaced by either EGM2 complete medium, or basal EBM2 medium supplemented with 5\% FCS (angiogenic factor starvation). After an additional 24 hours of culture, total RNA was prepared to analyze $L Y L 1$ and $T A L-1$ mRNA expression.

\section{In vitro tubulogenesis assays}

Individual HUVECs in basal medium containing $1 \%$ FCS were seeded into $1 \%$ collagen matrix as described, ${ }^{23}$ and activated by VEGF and bFGF (20 ng/mL) and Phorbol-12 Myristate 13-acetate (PMA; 80nM) to promote tubulogenesis.

\section{siRNA transfections}

Small interfering RNA (siRNA) were transfected in HUVECs as described. ${ }^{23}$ The sequences of duplex RNAs are presented in supplemental Table 1 (available on the Blood Web site; see the Supplemental Materials link at the top of the online article).

Lentivirus production and endothelial cell transductions are described in supplemental Methods.

\section{RNA preparation, and real-time polymerase chain reaction analysis}

Mouse tissues or tumors were lyzed in Trizol (Invitrogen), snap-frozen in liquid nitrogen and kept at $-80^{\circ} \mathrm{C}$ until used. The PureLink Micro-to-Midi Total RNA Purification System (Invitrogen) was used to extract total RNA from cultured cells following the manufacturer's instructions. RNA were primed with oligo(dT) and reverse transcribed with SuperScript II (Invitrogen). Polymerase chain reaction (PCR) primer sequences are shown in supplemental Table 2.

\section{Western blot analysis}

Western blots were performed as described ${ }^{25}$ using the following antibodies: the mouse anti-TAL-1 monoclonal antibody (mAb) 3BTL73, ${ }^{19}$ a rabbit anti- $\beta$-CATENIN polyclonal antibody (Sigma-Aldrich), a rabbit antiINTEGRIN- $\alpha 2$ polyclonal antibody (Millipore).

\section{Rap1 activity assays}

Rap1 activity was measured using the Rap1 activation assay kit (Millipore) following manufacturer's instructions. Briefly, guanosine-5'-triphosphate (GTP)-bound Rap1 was pulled down using RalGDS-Rap binding domain fused to glutathione-S-tranferase (GST) and immobilized to glutathione agarose beads. Precipitated GTP-bound Rap1 and total Rap1 were detected by immunoblotting with a polyclonal anti-Rap1.

\section{Animals}

C57BL/6 Lyl1-deficient mice $\left(\Delta^{\text {Lyl11}} / \Delta^{\text {Lyl1 }}\right)$, previously described, ${ }^{11}$ were maintained under pathogen-free conditions in our animal facility. All experiments were conducted by authorized personnel (agreements 34-308 for N.P., 34-217 for V.D. and 34-368 for V.P.) and approved by the Institutional Review Board at the Animal Facility of the Institut de Génétique Molécular de Montpellier. Mice genotypes were determined by PCR in the presence of $1 \mathrm{M}$ Betain, $1.3 \%$ dimethyl sulfoxide and $0.5 \mu \mathrm{M}$ of each primer (supplemental Figure 3).

\section{Tumor implantation}

LLC cells $\left(2.5 \times 10^{5}\right)$ kindly given by Philippe Huber (Commissariat à l'Énergie Atomique, Grenoble, France) or B16-F10 melanoma cells $\left(1 \times 10^{6}\right)$ were injected subcutaneously into the flank of 8-week-old mice. Mice were killed before tumor reached $10 \%$ of the total weight of the animal $\left(\approx 2000 \mathrm{~mm}^{3}\right)$. Tumors were snap-frozen in Tissue-Tek OCT embedding matrix (CML) and stored at $-80^{\circ} \mathrm{C}$ until they were processed for histologic analysis.

\section{Bone marrow and fetal liver transplantation experiments}

For bone marrow (BM) transplantation, C57B1/6 (Ly 5.1) male mice were used as recipients, whereas BM cells were prepared from C57B1/6 (Ly 5.2) wild-type (WT) or $\Delta^{\mathrm{Lyl1} /} / \Delta^{\mathrm{Lyll}}$ donors. BM cells were harvested from both femurs and tibias by repeat flushing of the bone cavity with phosphate buffer saline (PBS) supplemented with $2 \%$ fetal bovine serum and passage through a $70-\mu \mathrm{m}$ nylon cell strainer. For fetal liver (FL) transplantation, C57B1/6 (Ly 5.2) WT or Lyl1-deficient mice were used as recipients, whereas FL cells were obtained from day 14.5 postcoitus C57Bl/6 (Ly 5.1) embryos by mashing excised livers. Recipients were lethally irradiated with a unique 9.5-Gy dose and underwent transplantation with $2 \times 10^{6} \mathrm{BM}$ cells or $4 \times 10^{6} \mathrm{FL}$ cells, injected trough the retro-orbital sinus. Hematopoietic reconstitution after BM and FL cell injection was assessed 8 and 6 weeks after transplantation, respectively, through analysis of peripheral blood. To monitor engraftment, peripheral blood mononuclear cells (PBMCs) were double-stained with anti-CD45.2 (Ly5.2) FITC and anti-CD45.1 (Ly5.1) PE before analyzed by flow cytometry.

\section{Immunohistochemistry}

Cryostat sections were fixed in acetone/methanol at $-20^{\circ} \mathrm{C}$ for 15 minutes, rehydrated in PBS, and incubated in $3 \% \mathrm{H}_{2} \mathrm{O}_{2}$ solution for 7 minutes at room temperature. Nonspecific binding of antibody was blocked by incubation with PBS-20\% normal horse serum for 30 minutes. Endogenous biotins were blocked using the Avidin-Biotin Blocking kit (Vector Laboratories). Sections were stained for 1 hour with the rat anti-mouse CD31/ PECAM-1 mAb (1/250; clone MEC 13.3; BD Biosciences). Sections were incubated 45 minutes with biotinylated anti-rat Immunoglobulin Gs (IgGs; Vector Laboratories), washed, incubated with Extravidin Peroxidase, and revealed with 3-amino-9-ethylcarbazole (Sigma-Aldrich).

\section{Immunofluorescence}

Fixed cryostat sections were double-stained with the rat anti-mouse CD31 mAb, a rabbit anti-mouse NG2 polyclonal antibody (1/200; Millipore), or a mouse anti-mouse $\alpha$-SMA mAb (1/50; R\&D Systems). Primary antibodies were detected by a chicken anti-rat IgG Alexa 488, a donkey anti-rabbit IgG Alexa 555, and a chicken anti-mouse IgG Alexa 647, respectively (Invitrogen).

For TAL-1 immunostaining, purified 2 TL136 anti-TAL-1 mAb ${ }^{19}$ was labeled using the Dylight 649 antibody labeling kit (Perbio Science). Frozen sections were fixed with PBS containing 4\% formaldehyde, permeabilized with $0.5 \%$ Triton, and stained with labeled anti-TAL-1 mAb $(5 \mu \mathrm{g} / \mathrm{mL})$. Spleen cryosections were double-stained with a rat anti-mouse CD11b/CD18 mAb (1/200; Mac1, Millipore) and the anti-TAL-1 mAb. 
A

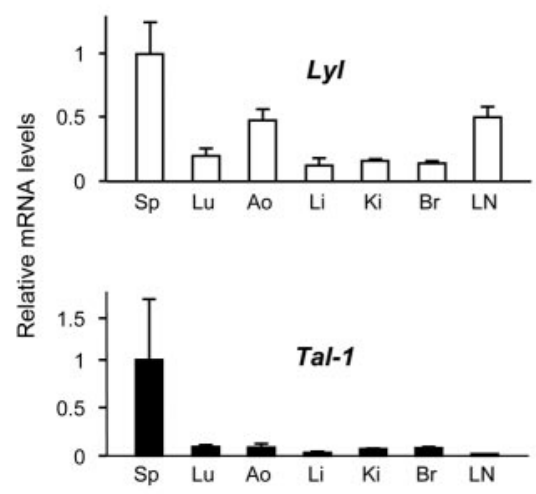

B
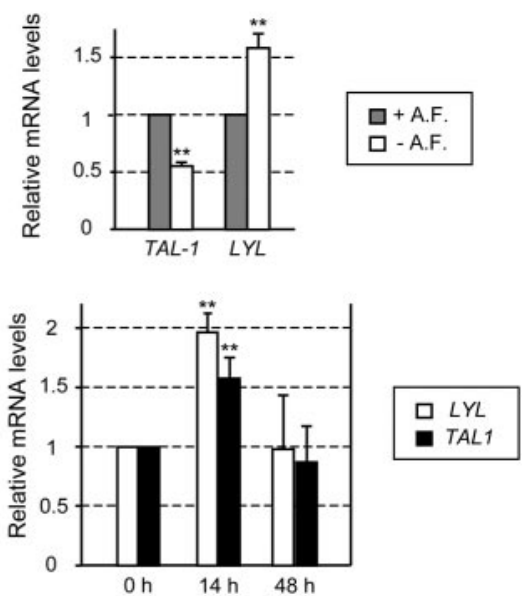

Figure 1. LYL1 is expressed in both angiogenic and quiescent adult endothelial cells. (A) Analysis of $L y / 1$ and Tal-1 mRNA in mouse adult tissues by qRT-PCR. Total RNA was extracted from different tissues derived from 4-week-old C57BL/6 mice (3 animals). cDNAs were amplified in triplicate by specific murine Ly/1 or Tal-1 primers and normalized to beta-Actin; means \pm SD are shown. Sp indicates spleen; Lu, lung; Ao, aorta; Li, liver; Ki, kidney; Br, brain; and LN, lymph nodes. mRNA levels in spleen were arbitrarily set at 1. (B top) $L Y L 1$ expression in quiescent conditions: confluent HUVECs were maintained in either complete medium containing angiogenic factors (+A. F.) or starved in basal medium supplemented by $5 \%$ of FCS (- A. F.) for additional 24 hours. (Bottom) $L Y L 1$ expression in angiogenic conditions. Exponentially growing HUVECs were seeded into collagen I matrix and activated by the addition of PMA, VEGF, and bFGF. Total RNAs were extracted at the indicated time points. $L Y L 1$ and TAL-1 mRNA levels were assessed by qRT-PCR. CDNAs were amplified in triplicate by specific human $L Y L 1$ or TAL-1 primers and normalized to GAPDH. Each bar is the mean \pm SD of mRNA levels relative to proliferating cells (set at 1) from 3 independent experiments performed in triplicate. ${ }^{\star \star} P<.01$

Nuclei were stained with $10 \mu \mathrm{g} / \mathrm{mL}$ of 4',6 diamidino-2-phenylinolole dihydrochloride (Sigma-Aldrich).

VE-Cadherin immunostaining of hTERT1 cells was performed as described ${ }^{23}$ using the Cadherin-5 mAb (1/125; Transduction Laboratories) and a chicken anti-mouse IgG Alexa 647 (Invitrogen). To visualize the fluorescence, we used a DM6000 Leica microscope, and images were acquired with Metamorph software (Molecular Devices) at room temperature.

\section{Extravasation of albumin-Evans blue within tumor tissues}

Mice bearing tumors between 200 and $500 \mathrm{~mm}^{3}$ were injected with $20 \mathrm{mg} / \mathrm{kg}$ Evans blue dye (EBD; Sigma-Aldrich) via the tail vein. Thirty minutes after injection, animals were anesthetized by intraperitoneal injection of $2 \mathrm{mg} / \mathrm{kg}$ bodyweight xylazine (Rompun 2\%; Bayer Pharma) and $50 \mathrm{mg} / \mathrm{kg}$ bodyweight ketamin (Imalgène 500; Merial) and the chest was opened. Mice were transcardially perfused with $50 \mathrm{~mL}$ of PBS-EDTA $5 \mathrm{mM}$ to remove excess of EBD. Tumors were excised, dried, weighed, and placed in formamide at $60^{\circ} \mathrm{C}$ for 36 hours. EBD in supernatants was quantified by spectrophotometry at $630 \mathrm{~nm}$.

\section{In vivo Matrigel plug assays}

$\mathrm{WT} / \Delta^{\mathrm{Lyl1}}$ and $\Delta^{\mathrm{Lyl1}} / \Delta^{\text {Lyl1 }}$ 9- to 12 -week-old mice were subcutaneously implanted with Matrigel supplemented with bFGF and heparin as described, ${ }^{22}$ and killed 10 or 11 days after implantation. Matrigel plugs were photographed and treated for histology. Matrigel plug sections $(20 \mu \mathrm{m})$ were probed with anti-CD31 antibody as described in "Immunochemistry," revealed with 3-amino-9-ethylcarbazole and counterstained with hematoxylin.

\section{Ex vivo aortic ring cultures}

Mouse aortic-ring cultures were essentially prepared as reported. ${ }^{26}$ The aortic rings were embedded in rat tail collagen gel and cultured at $37^{\circ} \mathrm{C}$ and $5 \% \mathrm{CO} 2$ in MCDB131 medium with 25mM NaHCO3 and 2\% autologous serum.

\section{Statistical analysis}

Differences between experimental groups were analyzed by unpaired Student $t$ test. $P$ less than .05 was considered statistically significant.

\section{Results}

\section{Lyl1 is highly expressed in endothelium-rich adult tissues}

We compared Lyll and Tal-1 expression in several tissues derived from C57BL/6 adult mice. Due to the absence of an anti-LYL1 antibody suitable for immunostaining or immunoblotting, this analysis was performed at the mRNA levels by quantitative RT-PCR (qRT-PCR). As expected, strong Lyll and Tal-1 expression was detected in the spleen, in keeping with the presence of numerous hematopoietic cells (Figure 1A). Lyll expression was observed in all other tissues tested and more particularly in endothelium-rich tissues such as aorta and lymph nodes, whereas Tal-1 mRNAs were barely detected. These data suggested that, unlike Tal-1, Lyll is active in mature quiescent endothelium.

\section{LYL1 expression occurred in both angiogenic and quiescent endothelial cells}

We then assessed whether LYL1 expression was modulated in HUVECs according to culture conditions that recapitulate proliferation, quiescence or angiogenesis. To reproduce the quiescence of endothelium, confluent HUVECs were starved of angiogenic growth factors for 24 hours, in the presence of serum (5\%) to avoid apoptosis. In these conditions, ECs tightly contacted each other and stopped to proliferate. As expected, HUVECs undergoing quiescence displayed a $50 \%$ decrease in TAL-1 mRNA levels, that we previously associated with a strong reduction in TAL-1 protein levels. ${ }^{22}$ In contrast, LYL1 mRNA levels were significantly increased ( $\sim 1.6$-fold, Figure 1B top).

The activation of ECs seeded within a 3-dimensional collagen matrix by VEGF, bFGF, and PMA induced angiogenic events leading to tubular structure formation. ${ }^{27}$ As observed for $T A L-1$, LYL1 mRNA levels were always present in these angiogenic conditions, with a significant up-regulation within the first 24 hours of tubulogenesis (Figure 1B bottom). Together these data show that LYL1 is always active in endothelial cells, independently of their activated or quiescent phenotype. 


\section{A}

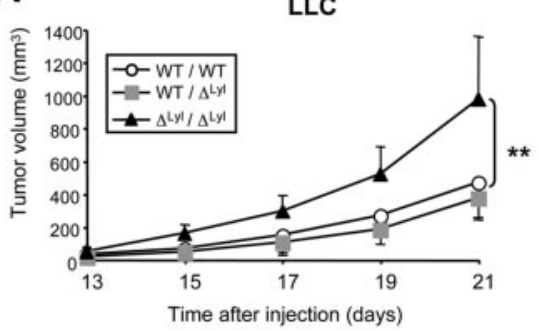

B

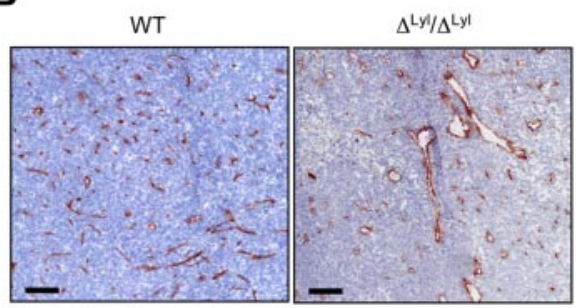

C

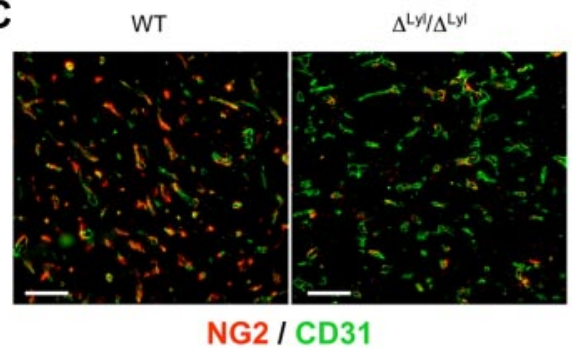

NG2 / CD31

D

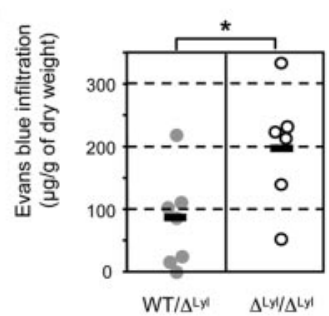

B16-F10
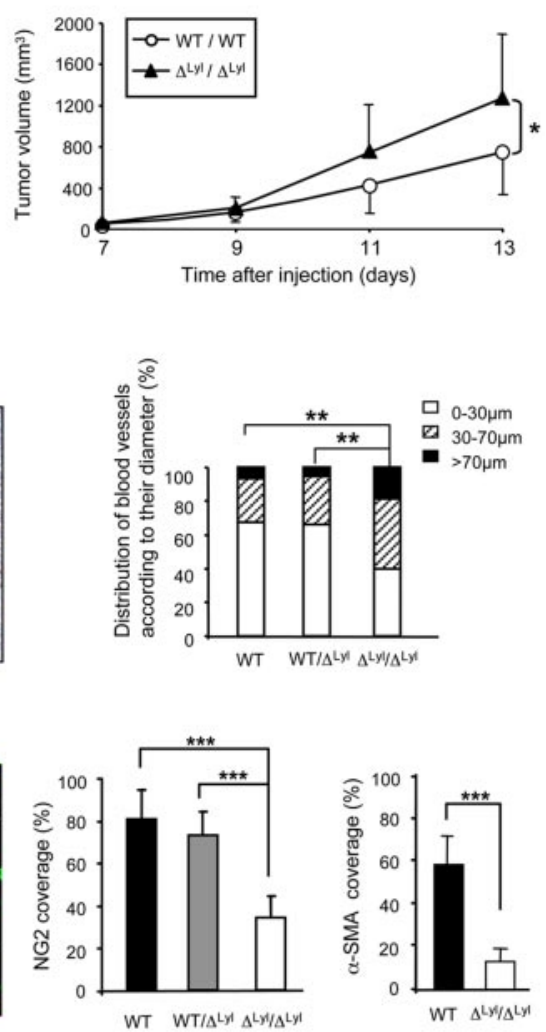

Figure 2. Accelerated tumor growth and immature tumor blood vessels in Lyl1-deficient mice. (A) Accelerated growth of syngeneic tumors in $\Delta^{\text {Lyl11/ }} \Delta^{\text {Lyl1 }}$ mice. (Left) Palpable tumors were measured every day using a caliper. The tumor volumes (in cubic millimeters) were calculated according to the formula: volume $=$ Pi/ $6 \times\left(\right.$ width) ${ }^{2}$

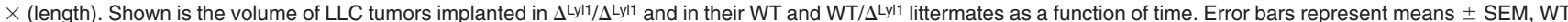
$(\mathrm{n}=7) ; \mathrm{WT} / \Delta^{\mathrm{Lyl1}}(\mathrm{n}=7) ; \Delta^{\mathrm{Lyl} 1} / \Delta^{\mathrm{Lyl1}}(\mathrm{n}=8)$. ${ }^{\star \star} P<.01$. Data are representative of 4 separate experiments. (Right) Shown is the volume of B16-F10 tumors implanted in

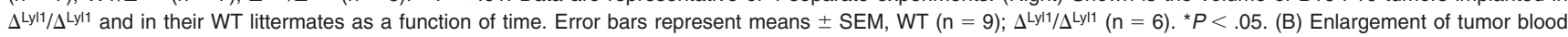
vessels in $\Delta^{\text {Lyl11/ }} \Delta^{\text {Lyl1 }}$ mice. The entire surfaces of CD31-stained sections of LLC tumor from $\Delta^{\text {Lyl11 }} / \Delta^{\text {Lyl1 }}$ and from their WT and WT/ $\Delta^{\text {Lyl1 }}$ littermates were visualized with a nanozoomer slide scanner controlled by the NDP.View software. (Left) Representative microscopy images of CD31 immunostaining of tumor sections showing enlargement of

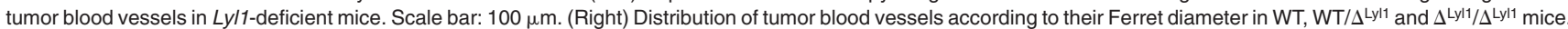
80 to 200 open vessels were selected per tumor section stained with anti-CD31 and their Ferret diameter was calculated using ImageJ software (National Institutes of Health). For each section, selected vessels were ranked according to their diameter and the following distribution was established: $<30 \mu \mathrm{m}, 30-70 \mu \mathrm{m}$, and $>70 \mu \mathrm{m}$. Analyzed tumors: WT $(n=7)$, WT/ $\Delta^{\text {Lyl1 }}(n=6), \Delta^{\text {Lyl11/ }} / \Delta^{\text {Lyl1 }}(n=9)$. ${ }^{* \star} P<.01$, using the $\chi^{2}$ test. (C) Reduced pericyte coverage of tumor blood vessels in $\Delta^{\text {Lyl1 }} / \Delta^{\text {Lyl1 }}$ mice. (Left) Microscopy images illustrating the severe reduction of pericyte coverage of tumor blood vessels from $\Delta^{\text {Lyl11/ }} \Delta^{\text {Lyl1 }}$ mice. LLC tumor sections were double-stained for the endothelial cell marker CD31 (green) and for the pericyte marker NG2 (red). Scale bar: $100 \mu \mathrm{m}$. (Right) The extent of vessel coverage by pericytes was determined on 4 to 6 random fields by measuring, with ImageJ software, the proportion of CD31-positive vessels covered by NG2- or $\alpha$-SMA-immunoreactive cells. NG2 coverage was calculated as the percentage of NG2-positive vessels compared with the number of CD31-positive vessels. The data are presented as the mean \pm SEM. Analyzed individual tumors: WT $(\mathrm{n}=7), \mathrm{WT} / \Delta^{\mathrm{Lyl1}}(\mathrm{n}=8) ; \Delta^{\mathrm{Lyl1} /} / \Delta^{\mathrm{Lyl1}}(\mathrm{n}=7) .{ }^{* \star \star} P<.001$. Tumor sections were double-stained for the endothelial cell marker CD31 and for the pericyte marker $\alpha-S M A($ see supplemental Figures 2-3). $\alpha$-SMA coverage was calculated as the percentage of $\alpha$-SMA-positive vessels compared with the number of CD31-positive vessels. The data are presented as the mean \pm SEM. Analyzed individual tumors: WT $(n=4), \Delta^{\text {Lyl11/ }} / \Delta^{\text {Lyl1 }}(n=6) .{ }^{* \star *} P<.001$. (D) Increased vascular permeability of tumors in $\Delta^{\text {Lyl11/ }} \Delta^{\text {Lyl1 }}$ mice $\Delta^{\text {Lyl11/ }} \Delta^{\text {Lyl1 }}$ and WT/ $\Delta^{\text {Lyl1 }}$ mice with LLC tumor sizes between 200 and $500 \mathrm{~mm}^{3}$ were used to measure tumor vascular permeability by Evans blue extravasation as an index of albumin leakage. Evans blue diffused within tumor was quantified at $630 \mathrm{~nm}$. The amount of EBD (micrograms per gram of dry weight) was calculated from standard curve to determine the concentration of extravasated dye in the tumor. The mean is represented as a black bar on this scatter plot. Each point represents data for a separate mouse: $\mathrm{WT} / \Delta^{\mathrm{Lyl1}}(\mathrm{n}=7), \Delta^{\mathrm{Lyl1}} / \Delta^{\mathrm{Lyl1}}(\mathrm{n}=6){ }^{*} P<.05$.

\section{Acceleration of tumor growth in Lyl1-deficient mice}

Homozygous genetic Lyll disruption in mice does not produce developmental abnormalities, but moderate hematopoietic defects. ${ }^{11,13,14}$ Adult Lyll-deficient mice are healthy and do not show obvious vascular defects. We took advantage of this mild pheno- type to investigate the biologic role of Lyll in vivo in adult angiogenesis, using tumors as a model of neovascularization. Syngeneic LLC cells were subcutaneously implanted in WT, heterozygous (WT/ $\left.\Delta^{\text {Lyl1 }}\right)$, and Lyll-deficient $\left(\Delta^{\text {Lyl1 }} / \Delta^{\text {Lyl1 }}\right)$ mice. Tumors grew at a similar rate in $\mathrm{WT}$ and $\mathrm{WT} / \Delta^{\mathrm{Lyll}}$ mice, but faster 
in $\Delta^{\text {Lyl1 }} / \Delta^{\text {Lyl1 }}$ mice resulting in larger tumors at all time points from day 15 to day 21 (Figure 2A). A similar acceleration of tumor growth was observed with B16-F10 melanoma cells implanted in $\Delta^{\text {Lyl1 }} / \Delta^{\text {Lyll }}$ mice, compared with WT mice.

\section{Tumor blood vessels in Lyl1-deficient mice display enlarged diameters}

We then investigated the mechanisms responsible for increased tumor growth in mice lacking Lyll by carrying out histologic analysis of tumor vascularization. Tumor sections were stained with an anti-CD31/PECAM antibody to reveal blood vessel infiltration. There was no difference in global CD31-staining, when expressed as a percentage of tumor area between WT, WT/ $\Delta^{\text {Lyl1 }}$ and

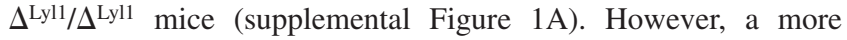
precise examination revealed frequent enlarged CD31-positive structures in $\Delta^{\mathrm{Lyl1}} / \Delta^{\mathrm{Lyl1}}$ tumors but not in WT and WT/ $\Delta^{\text {Lyl1 }}$ (Figure 2B and supplemental Figures 2-3). Quantitative analysis of vessel diameter was performed and showed a significant increase in the number of large vessels (diameter $>70 \mu \mathrm{m}$ ) in $\Delta^{\text {Lyl1 }} / \Delta^{\text {Lyl1 }}$ mice compared with WT and WT/ $\Delta^{\mathrm{Lyll}}$ mice $(18.6 \%$ vs $6.8 \%$ and $5.4 \%$, respectively). Conversely, small-size vessels (diameter $<30 \mu \mathrm{m}$ ) were more abundant in tumors induced in WT and WT/ $\Delta^{\text {Lyl1 }}$ mice than in $\Delta^{\text {Lyl1 }} / \Delta^{\text {Lyll }}$ mice $(67.4 \%, 66.1 \%$, and $39.7 \%$, respectively). This analysis shows that Lyll-deficiency leads to a general enlargement of vascular structures in LLC tumors.

\section{Tumor blood vessels in Lyl1-deficient mice are poorly covered and leaky}

Newly formed endothelial tubes are initially unstable and subsequently become stabilized through the formation of a perivascular matrix and the association with pericytes. ${ }^{28}$ To evaluate vessel coverage in the tumors, tumor sections were double-stained with anti-CD31 and an anti-NG2 antibody that recognizes pericytes. As reported, ${ }^{29,30}$ microvessels of LLC tumors grown in WT mice were nicely covered by mural cells, because a large majority $(80 \% \pm 14 \%)$ of CD31-structures were also stained with NG2 (Figure 2C and supplemental Figure 2). Tumor vessels from $\mathrm{WT} / \Delta^{\text {Lyl1 }}$ mice displayed similar NG2-coverage $(72.8 \% \pm 11.2)$. In contrast, tumor vessels from $\Delta^{\mathrm{Lyl1} /} \Delta^{\mathrm{Lyll}}$ mice were significantly less covered $(33.9 \% \pm 10.2)$ by NG2-positive mural cells. We also performed the analysis of $\alpha$-SMA marker (supplemental Figure 2), because it has been described to reflect a later stage of mural cell recruitment. ${ }^{30} 56 \% \mathrm{CD} 31$-positive vessels in tumors from WT mice were covered with $\alpha$-SMA-positive mural cells, while only $12 \%$ CD31-positive tumor vessels from Lyll-deficient mice were covered with $\alpha$-SMA-positive mural cells (Figure 2C). Similarly, vessels of B16-F10 tumors arising in $\Delta^{\text {Lyl1 }} / \Delta^{\text {Lyl1 }}$ mice were poorly covered, compared with WT (supplemental Figure 3). Altogether, these studies indicate that Lyll-deficiency leads to a strong reduction in the coverage of tumor blood vessels by mural cells.

Vascular permeability has been correlated to reduced mural cell recruitment to blood vessels in different pathologies including tumors. ${ }^{31}$ We therefore addressed whether the reduced recruitment of pericytes to tumor microvessels in mice lacking Lyll might affect tumor vascular permeability. As shown in Figure 2D, $\Delta^{\text {Lyl1 }} / \Delta^{\text {Lyl1 }}$ LLC tumors displayed a 2.4-fold increase in Evans blue extravasation compared with WT/ $\Delta^{\text {Lyl1 }}$ mice $(192.8 \mu \mathrm{g} / \mathrm{g}$ vs $80 \mu \mathrm{g} / \mathrm{g}$ tumor dry weight, respectively). Altogether, these data strongly suggest that reduced pericyte coverage of tumor vessels might be at the origin of increased vascular tumor leakage observed in $\Delta^{\text {Lyl1 } /} \Delta^{\text {Lyl1 }}$ mice.

\section{TAL-1, the VE-cadherin target gene and Angiopoietin-2 are up regulated in tumor vasculature of $L y / 1$-deficient mice}

Given that TAL-1 expression is limited to developing angiogenic vessels, ${ }^{18-20}$ and given the immature features of tumor vasculature in Lyll-deficient mice (Figure 2), we investigated Tal-1 expression in endothelial cells of LLC tumors arising in the 3 groups. For each piece of tumor tested, Tal-1 mRNA levels were expressed relative to CD31-PECAM mRNA levels used here as an endothelialspecific gene marker. There was no significant difference in $C D 31$ mRNA expression between the 3 groups in agreement with similar global CD31-immunostaining of the tumors (supplemental Figure 1). In contrast, Tal-1 mRNA expression was significantly up regulated $(\sim 2$-fold $)$ in $\Delta^{\text {Lyl1 } /} \Delta^{\text {Lyl1 }}$ tumors compared with WT and WT/ $\Delta^{\text {Lyl1 }}$ tumors (Figure 3A). Immunofluorescence analysis confirmed specific TAL-1 protein expression in the nucleus of ECs boarding the blood vessels of $\Delta^{\text {Lyl1 } /} \Delta^{\text {Lyl1 }}$ mice tumors (Figure 3A), but not of WT mice tumors in agreement with a previous study. ${ }^{21}$ Together, these data demonstrated that Tal-1 expression was sustained in tumor endothelial cells of Lyll-deficient mice.

We previously reported that TAL-1 activates VE-cadherin expression. ${ }^{23}$ Moreover, Angiopoietin-2 up-expression is associated with angiogenic vessels. We therefore investigated the expression at the mRNA levels of both genes in LLC tumors grown in the 3 genotypes (Figure $3 \mathrm{~B}$ ). Both VE-cadherin and Ang-2 mRNA levels showed a similar increase $(\sim 2$-fold $)$ in tumors from $\Delta^{\text {Lyl1 }} / \Delta^{\text {Lyll }}$ mice compared with WT mice tumors. Hence, in agreement with its angiogenic and immature features, tumor vasculature of Lyll-deficient mice exhibits a concomitant up-regulation of TAL- 1 and its target gene VE-cadherin, as well as Angiopoietin-2.

\section{The hematopoietic defects of Lyl1-deficient mice are not responsible for increased tumor growth and immaturity of tumor blood vessels}

LYL1 is active in several hematopoietic cell types, including B cells and immature myeloid cells ${ }^{32}$ that play important roles in tumor angiogenesis. ${ }^{33}$ Although the hematopoietic defects of $\Delta^{\text {Lyll }} / \Delta^{\text {Lyll }}$ mice are not severe, ${ }^{11}$ we could not exclude that they might affect directly tumor growth and angiogenesis. To evaluate this possibility, we carried out reciprocal transplantation of immature hematopoietic progenitors between WT and $\Delta^{L y l l} / \Delta^{L y l l}$ mice, and followed the growth of LLC tumors after hematopoietic reconstitution.

First, irradiated WT Ly5.1 recipients were transplanted with BM cells from either Ly5.2 WT or $\Delta^{L y l l} / \Delta^{L y l l}$ mice and subcutaneously injected with LLC cells after successful BM engraftment (8 weeks). LLC tumors grew at a similar rate in Ly5.1 mice transplanted with WT or Lyll-deficient BM cells, and tumor vessels from both Ly5.1 transplanted mice had similar NG2 and $\alpha$-SMA coverage (Figure 4A). These results show that $\Delta^{L y l l} / \Delta^{L y l l}$ BM cells cannot, by themselves, induce increased tumor growth associated with immature angiogenic vessels.

In a second set of experiments, irradiated Ly5.2 WT or Lyll-deficient recipients were transplanted with day-14.5 FL cells from Ly5.1 WT mice and subcutaneously injected with LLC cells after successful peripheral hematopoietic reconstitution (6 weeks). Compared with WT mice, at days 15 and 16 after injection, $\Delta^{\text {Lyl1 }} / \Delta^{\text {Lyl1 }}$ mice transplanted with WT FL stem cells exhibited larger tumors, which were associated with a significant reduction of vessel coverage (Figure 4B, and supplemental Figure 4). Together, these results demonstrate that the increased tumor growth and 
A
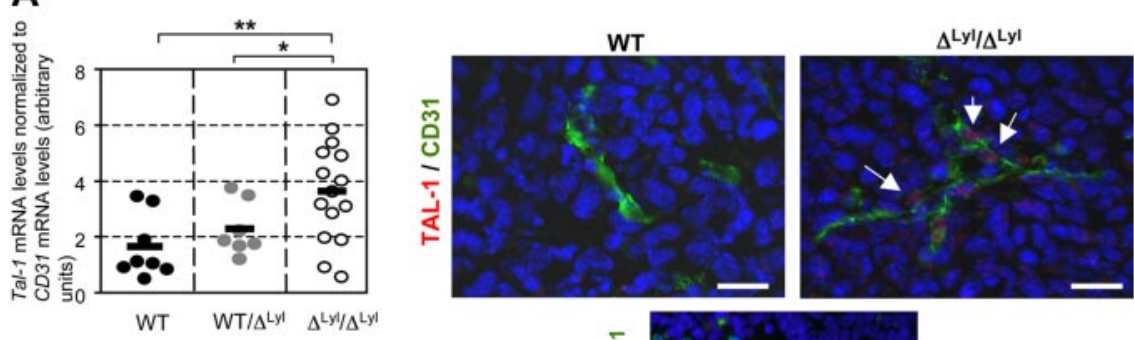

B
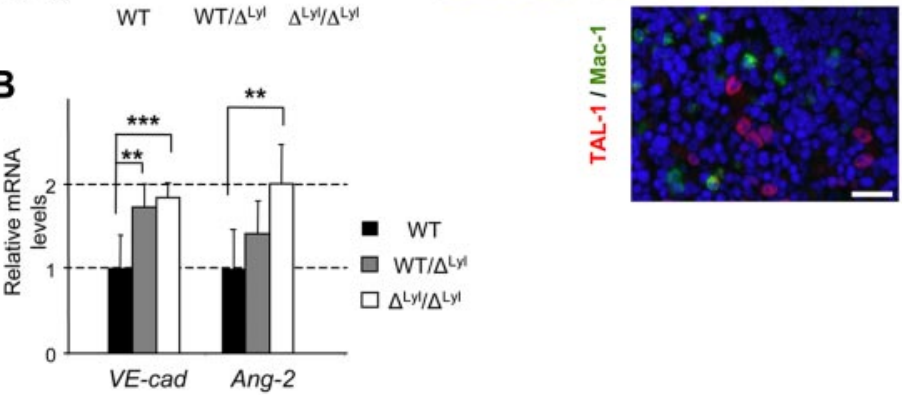

Figure 3. Up regulation of TAL-1, its VE-Cadherin target gene and Angiopoietin-2 in tumor vessels of Lyl1-deficient mice. (A) Endothelial Tal-1 expression in LLC tumors implanted in $\Delta^{\text {Lyl11/ }} \Delta^{\text {Lyl1 }}$, WT/ $\Delta^{\text {Lyl1 }}$ and WT mice. (Left) Total RNA was extracted from 1 or 2 pieces of tumors from mice of the 3 genotypes. Each point represents data for distinct piece of tumors: $\Delta^{\text {Lyl11/ }} \Delta^{\text {Lyl1 }}$ (14 pieces/9 tumors); WT/ $\Delta^{\text {Lyl1 }}$ (7 pieces/5 tumors); WT (8 pieces/6 tumors). cDNAs were amplified in triplicate by specific Tal-1. Shown are normalized Tal-1 mRNA levels relative to $C D 31$ mRNA levels (see supplemental Figure 1B) in each piece of tumor. The mean is represented as a black bar on this scatter plot. ${ }^{\star \star} P<.01 ;{ }^{*} P<.05$. (Right) Immunofluorescence analysis of TAL-1 protein in LLC tumors from WT and $\Delta^{\text {Lyl11}} / \Delta^{\text {Lyl1 }}$ mice. Representative microscopy images showing TAL-1 expression in the nucleus of endothelial cells boarding a blood vessel in a tumor of $\Delta^{\text {Lyl11/ }} \Delta^{\text {Lyl1 }}$ mice (white arrows), but not in tumor of their WT littermates. Tumor sections were double-stained for TAL-1 (red) and for blood vessel marker CD31 (green). Scale bar: $20 \mu \mathrm{m}$. (Bottom) TAL-1 expression in immature erythroid cells WT mice used here as positive control for TAL-1 staining. Spleen sections were double-stained for TAL-1 (red) and for the macrophage marker CD11b/CD18 (Mac1, green). Note the specific intense TAL-1 staining in the large nuclei of blast cells, but not in the smaller nuclei of lymphocytes or macrophages. Scale bar: $20 \mu \mathrm{m}$. (B) Total RNA was extracted from 1 or 2 pieces of tumors from mice of the 3 genotypes (as in panel A). cDNAs were amplified in triplicate by specific VE-cadherin or Ang-2 primers. VE-cadherin and Ang-2 mRNA levels were normalized to beta-Actin. Each bar is the mean \pm SD of mRNA levels relative to mRNA levels of WT mice-derived, set arbitrarily at $1{ }^{\star \star \star} P<.005$; ${ }^{\star \star} P<.01$
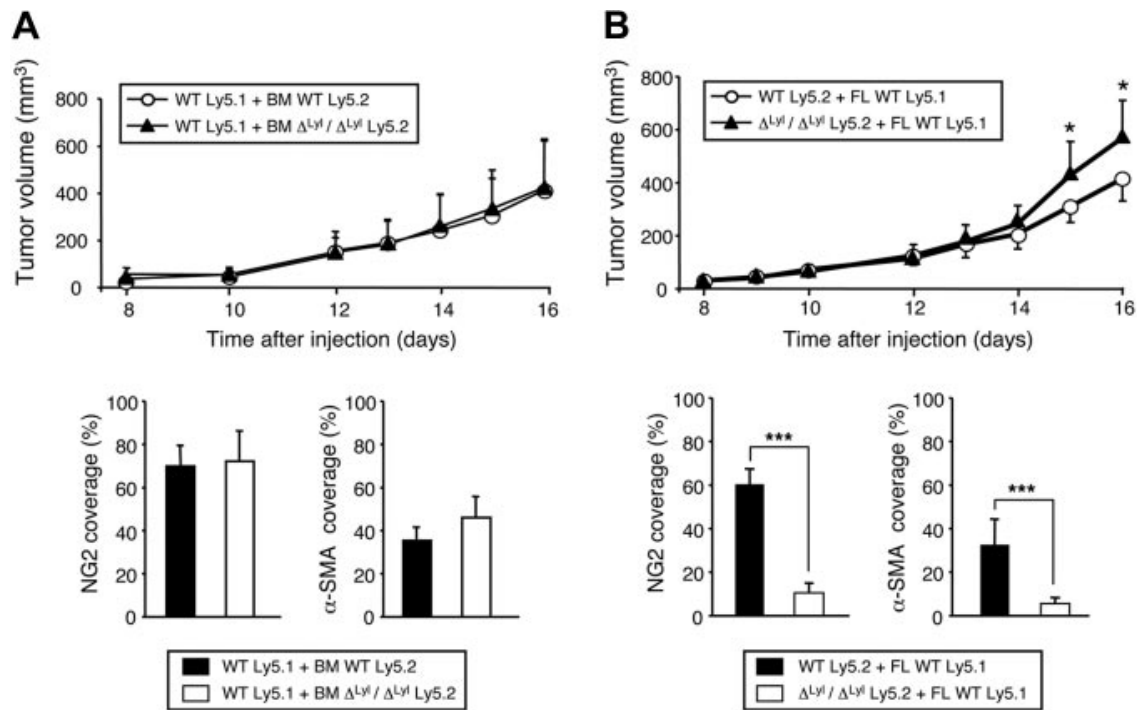

Figure 4. The hematopoietic defects of $\Delta^{\text {Lyl11} / \Delta^{L y l 1}}$ mice are not responsible for the accelerated tumor growth and immaturity of tumor blood vessels. (A top) Shown is

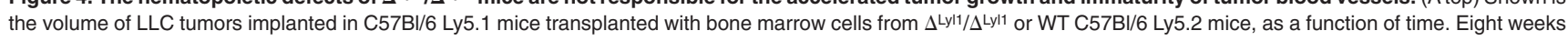
after transplantation, $86.9 \%( \pm 5.5 \%)$ and $77.4 \%( \pm 8.2 \%)$ of PBMCs were Ly5.2-positive in mice transplanted with BM cells from either WT or $L y / 1$-deficient mice, respectively. Error bars represent means \pm SEM, WT $(n=9) ; \Delta^{\text {Lyl11/ }} \Delta^{\text {Lyl1 }}(n=7)$. (Bottom) Quantization of mural cell coverage of tumor blood vessels of WT mice transplanted either with WT or $\Delta^{\text {Lyl11/ }} \Delta^{\text {Lyl1 }}$ mice BM cells, by immunofluorescence with NG2, or $\alpha$-SMA antibody. Vessel coverage was calculated as the percentage of NG2-, or $\alpha$-SMA, positive vessels compared with the number of CD31-positive vessels. The data are presented as the mean \pm SEM. Analyzed individual tumors: WT $(\mathrm{n}=5) ; \Delta^{\text {Lyl11/ }} \Delta^{\text {Lyl1 }}(\mathrm{n}=6)$; NG2 coverage: $70 \%( \pm 9.2 \%)$ and $72.2 \%( \pm 13.8 \%)$ for WT mice transplanted with WT and Lyl1-deficient BM cells, respectively; $\alpha-S M A$ coverage: $34.8 \%( \pm 5.8 \%)$ and $46.5 \%( \pm 9.5 \%)$ for

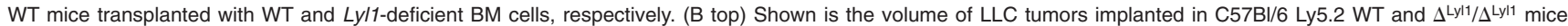
transplanted with fetal liver cells from C57BI/6 Ly5.1 WT mice, as a function of time. Six weeks after transplantation, $77.6 \%( \pm 9.1 \%)$ and $92.8 \%( \pm 1.9 \%)$ of PBMCs were Ly5.1-positive in Ly5.2 WT or Lyl1-deficient transplanted mice, respectively. Error bars represent means $\pm S E M, W T(n=6) ; \Delta^{\text {Lyl11/ }} \Delta^{\text {Lyl1 }}(\mathrm{n}=9)$. ${ }^{\star} P<.05$. $($ Bottom) Quantization of mural cell coverage of tumor blood vessels of either WT or $\Delta^{\text {Lyl11/ }} \Delta^{\text {Lyl1 }}$ mice transplanted with WT fetal liver cells by immunofluorescence (as in panel A). The data are presented as the mean \pm SEM. Analyzed individual tumors: WT $(n=6) ; \Delta$ Lyl $1 / \Delta$ Lyl $(n=6)$; NG2 coverage: $59.6 \%( \pm 7.8 \%)$ and $10.5 \%( \pm 4.3 \%)$ for WT and $\Delta^{\text {Lyl1 }} / \Delta^{\text {Lyl1 }}$ mice transplanted with WT FL cells, respectively. For $\alpha$-SMA coverage: $32.4 \%( \pm 11.7 \%)$ and $5.6 \%( \pm 2.5 \%)$ for WT and $\Delta^{\text {Lyl1 }} / \Delta^{\text {Lyl1 }}$ mice transplanted with WT FL cells, respectively. 
A

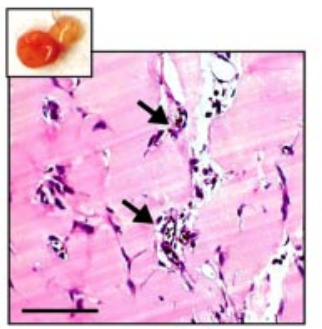

$\mathrm{WT} / \Delta^{\mathrm{Lyl}}$

B

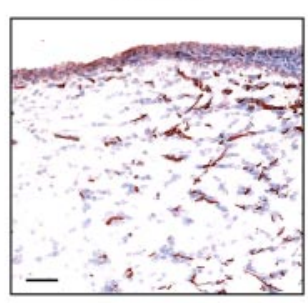

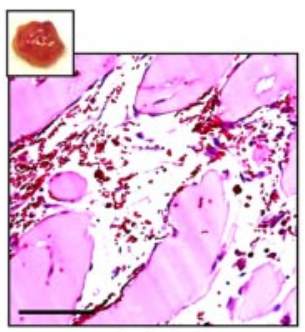

$\Delta^{\mathrm{Lyl}} / \Delta^{\mathrm{Lyl}}$

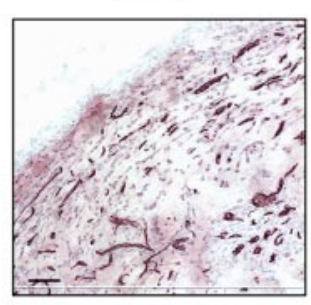

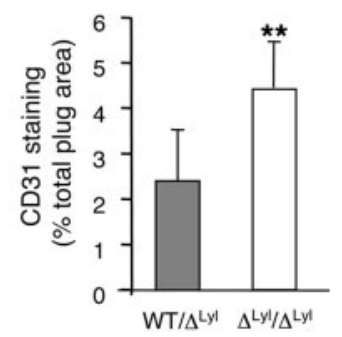

Figure 5. Increased angiogenesis in Matrigel plugs implanted in Lyl1-deficient mice. bFGF-containing Matrigel was subcutaneously implanted in both Lyl1-deficient and heterozygous mice (a total of 11 animals in each group in 2 experiments). Plugs were harvested at day 11, photographed (see supplemental Figure 4), and processed for histology. (A) Hematoxilin/Eosin staining of plug sections was visualized with a Nanozoomer slide scanner (Hamamatsu), and scanned images were analyzed with NDP.view software. Small insets show photograph of the corresponding Matrigel plug. Arrows indicate perfused small blood vessels in WT/ $\Delta^{\text {Lyl1 }}$ plug section. Scale bars: $100 \mu \mathrm{m}$. (B) CD31 infiltration of Matrigel plugs: The entire surface of CD31-stained plug sections

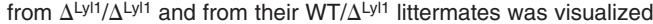
with a nanozoomer slide scanner controlled by the NDP.view software. (Left) Representative microscopy images of CD31 staining of plug sections from both genotypes. Scale bars: $100 \mu \mathrm{m}$. (Right) Entire plug sections were scanned and analyzed with ImageScope software (Aperio Technologies) using the "Positive Pixel count v9" algorithm. Shown is the quantification of CD31staining expressed as a percentage of total plug surface. The data are presented as the mean \pm SEM. Individual plugs from 2 independent experiments WT/ $\Delta^{\text {Lyl1 }}(\mathrm{n}=7), \Delta^{\text {Lyl11 }} / \Delta^{\text {Lyl1 }}(\mathrm{n}=6),{ }^{\star \star} P<.01$. angiogenesis observed in $\Delta^{\text {Lyll }} / \Delta^{\text {Lyll }}$ mice do not have a hematopoietic origin.

\section{Increased angiogenesis and enlargement of blood vessels in Matrigel implanted in Lyl1-deficient mice}

We then evaluated Lyll function in the well-characterized neovascularization model, Matrigel plug assays. At day 11, implants were photographed and processed for histologic studies. Macroscopic analysis showed that the majority of $\Delta^{\mathrm{Lyll}} / \Delta^{\mathrm{Lyll}}$ mice plugs displayed a strong angiogenic response compared with $\mathrm{WT} / \Delta^{\mathrm{Lyl} 1}$ plugs (see supplemental Figure 5). Histology of heterozygous mice implants showed the development of small caliber capillary structures, and the presence of red blood cells indicated that the neovessels were functionally perfused (Figure 5A). Although some

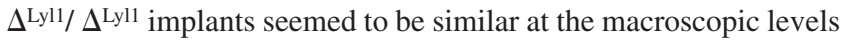
to WT/ $\Delta^{\text {Lyll }}$ implants, histology revealed great differences in the morphology of vascular structures. Blood vessels from $\Delta^{\text {Lyl1 } /} \Delta^{\text {Lyl1 }}$ implants were highly dilated and in many cases were organized into large vascular cavities engorged with blood and often surrounded with red blood cells, indicative of vascular leakiness (supplemental Figure 6A). Of note, the features of these vascular structures were reminiscent to those developed in $T A L-1$ overexpressing Matrigel (supplemental Figure 6B) as we previously described. ${ }^{22}$

Plug sections were stained with the anti-CD31 antibody to reveal blood vessel infiltration (Figure 5B). Plugs that displayed large vascular cavities were excluded, because they were not suitable for immunohistochemistry studies. Matrigel implants from $\Delta^{\text {Lyl1/ }} \Delta^{\text {Lyl1 }}$ mice showed a 2-fold increase in CD31-postive vessel infiltration compared with implants from WT/ $\Delta^{\text {Lyll }}$ mice. Thus, Lyll-deficiency causes an increased angiogenic response in subcutaneous Matrigel implants.

\section{Increased microvessel outgrowth from mice aortic explant of Lyl1-deficient mice}

We further explored the role of $L Y L 1$ in normal angiogenesis using the ex vivo aortic ring assay, in which we compared the angiogenic potential of aortic fragments derived from WT and Lyll-deficient mice. WT and $\Delta^{L y l l} / \Delta^{L y l l}$ aortic explants displayed similar outgrowth of myofibroblats (scattered cells, Figure 6A), most of them being $\alpha$-SMA-positive cells (supplemental Figure 7). Both WT and

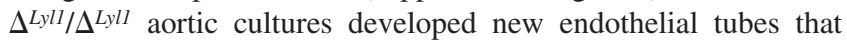
originated mostly from the 2 wounded edges (Figure 6A and rectilinear CD31-positive structures in supplemental Figure 7).
Image analysis of individual rings was performed to count the number of branchings and to measure the total surface occupied by new endothelial tubes (Figure 6B). Microvessels developed from $\Delta^{L y l l} / \Delta^{L y l l}$ aortic explants were more numerous and larger than those originating from WT aorta. Altogether, these studies indicate that Lyll-deficiency increases microvessel formation from aortic explants without affecting mural cell outgrowth.

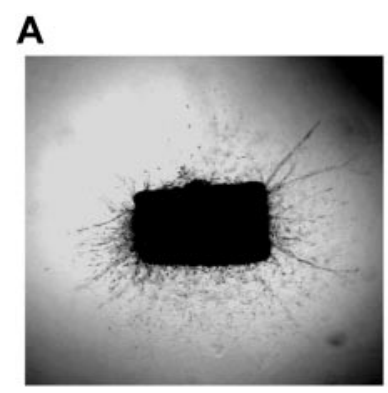

WT

\section{B}

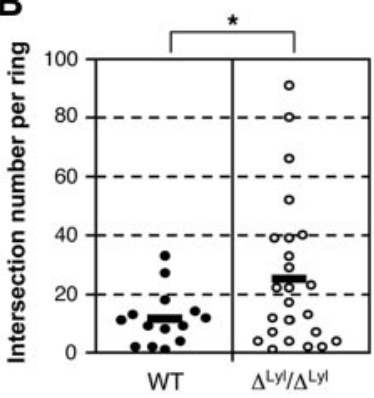

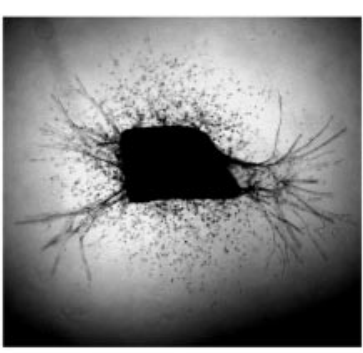

$\Delta^{\mathrm{Ly} I} / \Delta^{\mathrm{LyI}}$

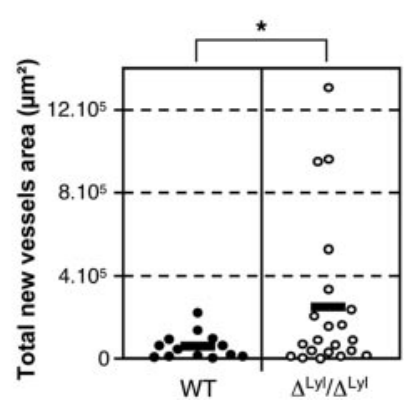

Figure 6. Lyl1-deficiency increases angiogenic potential of mice aortic explant. (A) Photomicrographs show the angiogenic response of a 5-day culture collagen-

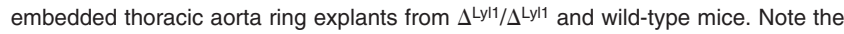
outgrowth of scattered myelofibroblast cells ( $\alpha$-SMA-positive cells, supplemental Figure 6) and endothelial tubules (CD31-positive cells, supplemental Figure 6) in both genotypes. (B) Images of microvessel outgrowth from aortic explants were captured at day 5 of culture with a Canon Powershot A650 digital camera mounted on an inverted phase contrast Axiovert25 microscope (Zeiss). The angiogenic response was determined for each individual aortic ring explant by quantifying the number of intersections of growing microvessels (left) and by measuring the total area occupied by the newly formed microvessels (right). Each point represents data for distinct

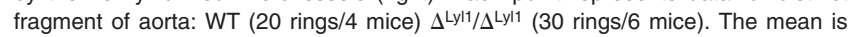
represented as a black bar on this scatter plot. ${ }^{*} P<.05$. 
A

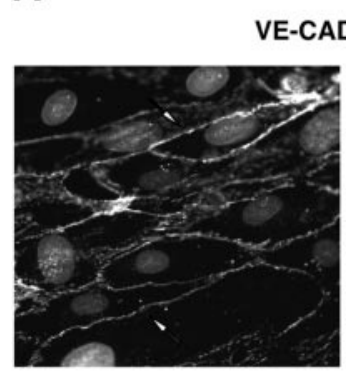

ShRNA-CTL

C

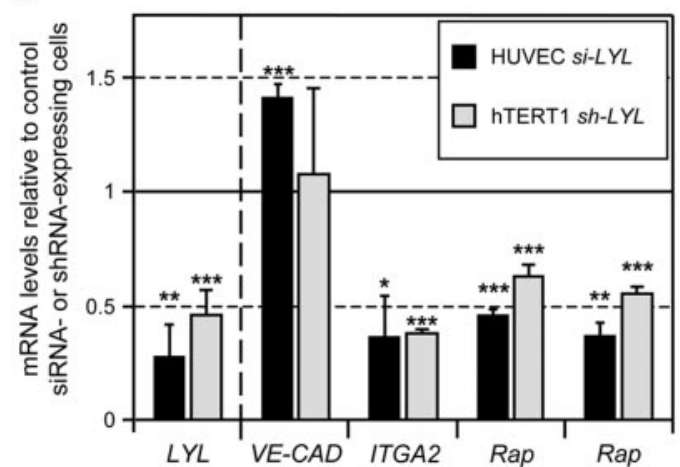

B

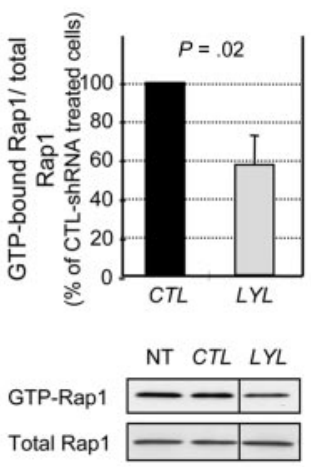

D

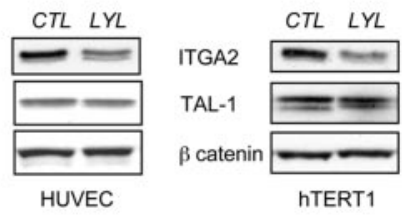

Figure 7. $L Y L 1$ controls the expression of molecules involved in the formation and stabilization of adherens junctions. (A) $L Y L 1$-depletion affects the assembly and maturation of adherens junctions. hTERT1 cells were transduced with lentiviruses encoding either control shRNA or LYL1 shRNA, and puromycin-resistant cell populations were established. Confluent monolayers of the indicated population were immunostained with a VE-Cadherin antibody and vizualized with Alexa 647-conjugated secondary antibody. Note the continuous and regular staining on CTL-hTERT1 cell perimeters (arrows) and the presence of gaps between adjacent cells (arrowheads) leading to an irregular staining. (B) $L Y L 1$ depletion reduces constitutive activation of Rap1. Whole cell extract prepared from shRNA-transduced hTERT1 were assayed for RAP1 activity as described in "Rapactivity assay." Scanned autoradiographs were quantified using Image J to determine the ration GTP-bound Rap1/total Rap1 for each extract. Bars show means \pm SD of the ratio GTP-bound Rap1/total-Rap1 of 3 independent experiments. shRNA CTL-treated cell ratio was arbitrarily set at $100 \%$. Images shown are representative of the 3 experiments. Vertical lines have been inserted to indicate a repositioned gel lane. (C) HUVECs were treated with $L Y L 1$ or control $H L A-A$ siRNA and total RNA were prepared 48 hours after transfection. hTERT1 cells were transduced with lentiviruses encoding either control shRNA or LYL1 shRNA, and puromycin-resistant cell populations were established. mRNA levels of the indicated gene in siRNA-treated HUVEC (black bars) or in shRNA-transduced hTERT1 (gray bars) were assessed by qRT-PCR. cDNAs were amplified by specific primers and normalized to GAPDH. VE-CAD, ITGA2, Rap-GEF1, Rap-GEF2, genes encoding VE-CADHERIN, INTEGRIN- $\alpha 2$, C3G and DOCK4 proteins, respectively. Each bar is the mean \pm SD of mRNA levels relative to control HLA-A siRNA-treated HUVECs (3 independent experiments) or to hTERT1 cells transduced with control shRNA-lentivirus, which were set at $100 \%$. ${ }^{* \star *} P<.005 ;{ }^{* *} P<.01 ;{ }^{*} P<.05$ by Student $t$ test. (D) $L Y L 1$-silencing causes down-expression of INTEGRIN- $\alpha 2$ : HUVECs or hTERT1 cells were transduced with lentiviruses encoding either control shRNA or shRNA targeting LYL1. Whole cell proteins prepared from puromycin-resistant cell populations were analyzed by immunoblotting for INTEGRIN- $\alpha 2$ and TAL-1 protein expression. beta-CATENIN protein expression was used to control protein loading.

\section{LYL1-silencing reduces the expression of several molecules that contribute to maturation of endothelial adherens junctions}

Our above results (Figure 4) showed that the immature phenotype of neovasculature in $\Delta^{\text {Lyll }} / \Delta^{\text {Lyll }}$ mice, that is, increased permeability and poor pericyte coverage, is the consequence of defects intrinsic to endothelial cells. To investigate the mechanisms by which LYL1 regulates EC phenotype, we evaluated the consequences of $L Y L 1$ depletion in human ECs. LYL1-silencing was mediated either by siRNA transfection (HUVECs) or by transduction of lentiviruses encoding shRNA (hTERT1). As expected from our above results (Figures 2B and 6A), LYL1-silencing did not affect endothelial tubulogenesis in 3-dimensional collagen matrix (not shown), confirming that LYL1 is not required for this process. The assembly and stabilization of endothelial junctions are determinant for the maturation of new vascular structures. ${ }^{34}$ To address whether LYL1 impacts the organization of adherens junctions, we compared the immunostaining with anti-VE-Cadherin of shCTLand shLYL1-transduced hTERT1 cells (Figure 7A). Both cell populations showed clustering of VE-Cadherin at intercellular junctions. However, in $L Y L 1$-depleted cells, the staining was often discontinuous and many gaps were present between adjacent cells, compared with the continuous VE-Cadherin staining of CTLhTERT1 cell perimeters.

Given the essential role of the small GTPase Rap1 for VECadherin-dependent adhesion ${ }^{35}$ and for the stabilization of established endothelial junctions, ${ }^{36,37}$ we investigated whether LYL1 influences Rap1 activity in hTERT1 cells, by a pull-down assay using a GST fusion protein of Rap1-binding domain of RalGDS. Basal levels of activated Rap1 (GTP-bound) were significantly reduced $(\sim 40 \%)$ in LYL1-depleted cells compared with control hTERT1 cells (Figure 7B). We then assessed whether LYL1 modulates the expression of genes encoding guanine nucleotide exchange factors (GEFs) that activate Rap1. As shown in Figure 7C, LYL1-depletion in both HUVECs and hTERT1 cells caused a significant reduction in Rap-GEF $1 / C 3 G$ and Rap-GEF2/DOCK4 mRNA levels. In agreement with VE-Cadherin staining (Figure 7A), LYL1-knockdown did not change VE-Cadherin mRNA levels in hTERT1, and produced a 1.4-fold stimulation of VE-Cadherin mRNA levels in HUVECs (Figure 7C). LYL1-depletion in HUVECs and in hTERT1 cells also caused a strong decrease in ITGA2 mRNA levels $(\sim 60 \%)$, together with a reduced INTEGRIN- $\alpha 2$ protein expression (Figure 7D), which has an important role in 
endothelial cell adhesion and stability. ${ }^{38}$ Of note, LYL1 depletion did not change TAL-1 protein levels in both endothelial cell types.

Collectively, these data show that $L Y L 1$ depletion decreased the expression of several important mediators of AJ assembly and stabilization, without reducing the major constituent of AJs.

\section{Discussion}

The objective of this study was to delineate the role of $L Y L 1$ in the endothelial lineage in adulthood. Loss-of-function experiments identified that $L Y L 1$, dispensable for initiating angiogenesis, is required during the later steps of postnatal remodeling to promote maturation of newly formed blood vessels.

Whereas Lyll activity was described in developing vasculature in embryos, ${ }^{17}$ its expression in adult endothelium was unknown. We described here that Lyll is active in all adult mice tissues tested where quiescent stabilized vasculature dominates, in contrast to Tal-1, which is only expressed in developing vessels. ${ }^{18-20}$ In vitro experiments confirmed that $L Y L 1$ expression occurs in quiescent ECs, but also in activated angiogenic ECs. The mild phenotype of Lyll-deficient mice gave us the possibility to investigate the role of this transcription factor in adult angiogenesis. We found that Lyll-deficiency causes an increased angiogenic response in 3 different models, ie implanted tumors, Matrigel plug assays and aortic ring assays.

Importantly, syngeneic LLC and B16-F10 tumors grew faster in Lyll-deficient mice than in their control or heterozygous littermates. Although tumor blood vessel density and areas were comparable, the architecture of tumor blood vessels from $\Delta^{\text {Lyl1 }} / \Delta^{\text {Lyl1 }}$ mice exhibited angiogenic features, that is, poor coverage, increased vascular leakage, lumen enlargement and persistent Tal-1 expression. This sustained angiogenesis is likely to promote tumor growth in $\Delta^{\text {Lyl1 }} / \Delta^{\text {Lyll }}$ mice. Of importance, reciprocal BM or FL transplantations demonstrate that the higher tumor rate and reduced vessel coverage were not due to hematopoietic defects of $\Delta^{\text {Lyl11/ }} \Delta^{\text {Lyl1 }}$ mice. Caveolin-1-deficient mice display a similar increased permeability of tumor vasculature that was correlated with larger LLC tumors, ${ }^{31}$ and treatments of tumor-bearing mice with molecules that reduce tumor vascular leakage also reduce tumor growth. ${ }^{31,39,40}$ Thus, the permeable vasculature, by allowing macromolecules to extravasate into the tumor interstitium, presumably also contributes to accelerated tumor growth in $L y l 1$-deficient mice.

Our data suggest that Lyll is required to limit the development of vascular lumen. Indeed, developing vessels in tumors as well as in Matrigel plugs and aortic rings from $\Delta^{\text {Lyl1 }} / \Delta^{\text {Lyll }}$ mice have larger diameters than in WT mice. Noteworthy, Matrigel implanted in $\Delta^{\text {Lyl1 }} / \Delta^{\text {Lyl1 }}$ mice display abnormal dilated vascular structures reminiscent to those previously observed in $T A L-1$ overexpressing plugs. ${ }^{22}$ We found a significant increase in Tal-1 expression at both mRNA and protein levels in vessels of tumors developed in Lyll-deficient-mice. It is unlikely that LYL1 directly influences Tal-1 expression in maturing vessels, because $L Y L 1$ silencing in human ECs does not change significantly TAL-1 protein levels (Figure 7). Therefore, Tal-1 up regulation in tumors may rather reflect vessel immaturity caused by sustained angiogenesis.

In keeping with the recent identification of $V E$-cadherin as a direct TAL-1 target, ${ }^{23} \Delta^{\text {Lyl1 }} / \Delta^{\text {Lyl1 }}$ mice tumors exhibit a concomitant up-expression of Tal- 1 and $V E$-cad, and $L Y L 1$ depletion in HUVECs slightly up regulates $V E c a d$ mRNA levels. Hence, both the absence of Lyll and simultaneous Tal-1 up regulation in tumor ECs may produce excessive VE-Cadherin. A recent study reveals that the aortic lumen develops extracellularly between adjacent ECs through the initial recruitment of CD34-sialomucins to the cell-cell contact, which is mediated by VE-Cadherin. ${ }^{41}$ Consequently, excessive VE-cadherin expression at the endothelial surface of vessels forming in $\Delta^{\text {Lyll }} / \Delta^{\text {Lyll }}$ mice might contribute to an exaggerated lumen development.

Tumors in $\Delta^{\text {Lyll }} / \Delta^{\text {Lyll }}$ mice also exhibit increased expression of the gene encoding the proangiogenic factor ANG2. The angiopoietin/Tie2 axis plays a central role in vessel maturation and stabilization. ${ }^{42}$ ANG1 acts as a Tie 2 agonist to promote and maintain mature blood vessels, while ANG2 acts a Tie2-antagonist, and its increased production by angiogenic ECs destabilizes vessel coverage by pericytes. ${ }^{43}$ One possibility is that a local excess of VE-Cadherin and ANG2, that both regulate endothelial responses to $\mathrm{VEGF},{ }^{34}$ may inhibit pericyte coverage and, as a consequence, vessel maturation. ${ }^{44}$

Our data strongly suggest that LYL1 serves as a stabilizing signal for developing vessels. Indeed, we identified several downstream LYL1 targets in ECs that operate in different pathways promoting assembly and maturation of endothelial junctions: (1) INTEGRIN- $\alpha 2$, which stabilizes nascent tubular structures through mediating cell adhesion to the extracellular matrix (reviewed in Avraamides et $\mathrm{al}^{38}$ ); (2) Rap1-GEFs, C3G, and Dock4 that function, through activating Rap1, at different levels in network signaling cell junction maturation (reviewed in Kooistra et $\mathrm{al}^{36}$ and Pannekoek et $\mathrm{al}^{37}$ ). Therefore, to explain the immature and highly angiogenic phenotype of the vessels neo-formed in $\Delta^{\text {Lyl1 }} / \Delta^{\text {Lyl1 }}$ mice, we propose that a concomitant reduction of these molecules in Lyll-lacking ECs contributes to impaired maturation of endothelial junctions.

Our data establish that Lyll expression occurs in both angiogenic and mature vessels, suggesting that LYL1 participates to the continued maintenance of the quiescent vessels. Lyll is dispensable for vascular development, indicating that its loss is compensated by other functionally similar factors that contribute to angiogenesis, namely Tal-1 that is coexpressed with Lyll in the developing vasculature. ${ }^{17}$ However, further studies are required to investigate whether Lyll-deficiency generates minor vascular anomalies in adult tissues where Tal-1 is supposed to be inactive.

Finally, our findings suggest possible medical implications. Transient normalization of tumor vasculature is emerging as a therapeutic option to improve drug delivery in anticancer treatment. ${ }^{45}$ A significant increase in vascular permeability is a hallmark of inflammatory diseases such as acute lung injury, sepsis, or epilepsy. ${ }^{46,47}$ Hence, strategies designed to increase $L Y L 1$ activity should be considered to promote or improve endothelial barrier in these pathologic situations.

\section{Acknowledgments}

We are grateful to Jean-Marie Blanchard for constant support, and to Luisa Dandolo for critical reading of the manuscript. We are indebted to the Montpellier-RIO imaging platform (Montpellier, France) and to the Transgenese et Techniques associées platform core facilities for animal experiments. We thank Patricia Cavalier for her expert assistance with histology studies, and Philippe Clair for his help in high throughput qPCR experiments (IFR22, Montpellier). We are grateful to Chamroeun Sar for his help in imaging analyses. N.P. was supported by successive grants from the French Minister of Education and the Ligue Nationale Contre le Cancer (France), R.E.-H. was supported by grants from the Ligue Régionale Contre le Cancer (Hérault, France) and the Conseil 
National de Recherche Scientifique (Liban), and is now a recipient of the Association pour la Recherche sur le Cancer (ARC; France). D.M. and V.P. are supported by Inserm.

This work was funded by grants from ARC and Institut National du Cancer (France).

\section{Authorship}

Contribution: All authors analyzed data; N.P., V.D., and V.P. performed animal studies; R.E.-H.,V.D., C.D., and P.C. performed molecular experiments; F.S. provided Lyll-deficient mice; and D.M. and V.P. conceived and designed the study and wrote the manuscript.

Conflict-of-interest disclosure: The authors declare no competing financial interests.

The current affiliation for N.P. is Institut de Recherche en Cancérologie de Montpellier, Montpellier, France.

Correspondence: Danièle Mathieu or Valérie Pinet, Institut de Génétique Moléculaire de Montpellier, UMR 5535, CNRS, 1919 route de Mende, 34293 Montpellier cedex 5, France; e-mail: daniele.mathieu@igmm.cnrs.fr or valerie.pinet@igmm.cnrs.fr.

\section{References}

1. Baer R. TAL1, TAL2 and LYL1: a family of basic helix-loop-helix proteins implicated in T cell acute leukaemia. Semin Cancer Biol. 1993;4(6):341347.

2. Robb L, Lyons I, Li R, et al. Absence of yolk sac hematopoiesis from mice with a targeted disruption of the scl gene. Proc Natl Acad Sci U S A. 1995;92(15):7075-7079.

3. Shivdasani RA, Mayer EL, Orkin SH. Absence of blood formation in mice lacking the T-cell leukaemia oncoprotein tal-1/SCL. Nature. 1995; 373(6513):432-434

4. Porcher C, Swat W, Rockwell K, Fujiwara Y, Alt FW, Orkin SH. The T cell leukemia oncoprotein SCL/tal-1 is essential for development of all hematopoietic lineages. Cell. 1996;86(1):47-57.

5. Robb L, Elwood NJ, Elefanty AG, et al. The scl gene product is required for the generation of all hematopoietic lineages in the adult mouse. EMBO J. 1996;15(16):4123-4129.

6. Visvader JE, Fujiwara Y, Orkin SH. Unsuspected role for the T-cell leukemia protein SCL/tal-1 in vascular development. Genes Dev. 1998;12(4): 473-479.

7. Gering M, Rodaway AR, Gottgens B, Patient RK, Green AR. The SCL gene specifies haemangioblast development from early mesoderm. EMBO J. 1998;17(14):4029-4045.

8. Porcher C, Liao EC, Fujiwara Y, Zon LI, Orkin SH Specification of hematopoietic and vascular development by the bHLH transcription factor SCL without direct DNA binding. Development. 1999; 126(20):4603-4615.

9. Gering M, Yamada Y, Rabbitts TH, Patient RK. Lmo2 and Scl/Tal1 convert non-axial mesoderm into haemangioblasts which differentiate into endothelial cells in the absence of Gata1. Development. 2003;130(25):6187-6199.

10. Patterson LJ, Gering M, Patient R. Scl is required for dorsal aorta as well as blood formation in zebrafish embryos. Blood. 2005;105(9):3502-3511.

11. Capron $C$, Lecluse $Y$, Kaushik AL, et al. The SCL relative $L Y L-1$ is required for fetal and adult hematopoietic stem cell function and B-cell differentiation. Blood. 2006;107(12):4678-4686.

12. Schlaeger TM, Schuh A, Flitter S, et al. Decoding hematopoietic specificity in the helix-loop-helix domain of the transcription factor SCL/Tal-1. Mol Cell Biol. 2004;24(17):7491-7502.

13. Souroullas GP, Salmon JM, Sablitzky F, Curtis DJ, Goodell MA. Adult hematopoietic stem and progenitor cells require either Lyl1 or Scl for survival. Cell Stem Cell. 2009;4(2):180-186.

14. Chan WY, Follows GA, Lacaud G, et al. The paralogous hematopoietic regulators Lyl1 and Scl are coregulated by Ets and GATA factors, but Lyl1 cannot rescue the early $\mathrm{Scl}-/-$ phenotype. Blood. 2007;109(5):1908-1916.

15. Ferrier R, Nougarede R, Doucet S, KahnPerles B, Imbert J, Mathieu-Mahul D. Physical interaction of the bHLH LYL1 protein and NF-kappaB1 p105. Oncogene. 1999;18(4):995-1005.

16. San-Marina S, Han Y, Suarez Saiz F, Trus MR,
Minden MD. Lyl1 interacts with CREB1 and alters expression of CREB1 target genes. Biochim Biophys Acta. 2008;1783(3):503-517.

17. Giroux S, Kaushik AL, Capron C, et al. Iyl-1 and tal-1/scl, two genes encoding closely related bHLH transcription factors, display highly overlapping expression patterns during cardiovascular and hematopoietic ontogeny. Gene Expr Patterns. 2007;7(3):215-226.

18. Kallianpur AR, Jordan JE, Brandt SJ. The SCL TAL-1 gene is expressed in progenitors of both the hematopoietic and vascular systems during embryogenesis. Blood. 1994;83(5):1200-1208.

19. Pulford K, Lecointe N, Leroy VK, Jones M, Mathieu MD, Mason DY. Expression of TAL-1 proteins in human tissues. Blood. 1995;85(3): 675-684.

20. Chetty R, Dada MA, Boshoff $\mathrm{CH}$, et al. TAL-1 protein expression in vascular lesions. J Pathol. 1997;181(3):311-315

21. Tang T, Shi Y, Opalenik SR, et al. Expression of the TAL1/SCL transcription factor in physiological and pathological vascular processes. J Pathol. 2006;210(1):121-129.

22. Lazrak M, Deleuze V, Noel D, et al. The bHLH TAL-1/SCL regulates endothelial cell migration and morphogenesis. J Cell Sci. 2004;117(Pt 7): 1161-1171

23. Deleuze V, Chalhoub E, El-Hajj R, et al. TAL-1/ SCL and its partners E47 and LMO2 up-regulate VE-cadherin expression in endothelial cells. $\mathrm{Mol}$ Cell Biol. 2007;27(7):2687-2697.

24. Yang J, Chang E, Cherry AM, et al. Human endothelial cell life extension by telomerase expression. J Biol Chem. 1999;274(37):26141-26148.

25. Leroy-Viard K, Vinit MA, Lecointe N, et al. Loss of TAL-1 protein activity induces premature apoptosis of Jurkat leukemic T cells upon medium depletion. EMBO J. 1995;14(10):2341-2349.

26. Masson VV, Devy L, Grignet-Debrus C, et al. Mouse Aortic Ring Assay: A New Approach of the Molecular Genetics of Angiogenesis. Biol Proced Online. 2002;4:24-31.

27. Davis GE, Bayless KJ, Mavila A. Molecular basis of endothelial cell morphogenesis in threedimensional extracellular matrices. Anat Rec 2002;268(3):252-275.

28. von Tell D, ArmulikA, Betsholtz C. Pericytes and vascular stability. Exp Cell Res. 2006;312(5):623-629.

29. Morikawa S, Baluk P, Kaidoh T, Haskell A, Jain RK, McDonald DM. Abnormalities in pericytes on blood vessels and endothelial sprouts in tumors. Am J Pathol. 2002;160(3):985-1000.

30. Nasarre P, Thomas M, Kruse K, et al. Hostderived angiopoietin-2 affects early stages of tumor development and vessel maturation but is dispensable for later stages of tumor growth. Cancer Res. 2009;69(4):1324-1333.

31. Lin MI, Yu J, Murata T, Sessa WC. Caveolin-1deficient mice have increased tumor microvascular permeability, angiogenesis, and growth. Cancer Res. 2007;67(6):2849-2856.

32. Visvader J, Begley CG, Adams JM. Differential expression of the LYL, SCL and E2A helix-loophelix genes within the hemopoietic system. Oncogene. 1991;6(2):187-194.

33. Murdoch C, Muthana M, Coffelt SB, Lewis CE. The role of myeloid cells in the promotion of tumour angiogenesis. Nat Rev Cancer. 2008;8(8): 618-631.

34. Dejana E, Tournier-Lasserve E, Weinstein BM The control of vascular integrity by endothelial cell junctions: molecular basis and pathological implications. Dev Cell. 2009;16(2):209-221.

35. Fukuhara S, Sakurai A, Sano H, et al. Cyclic AMP potentiates vascular endothelial cadherinmediated cell-cell contact to enhance endothelial barrier function through an Epac-Rap1 signaling pathway. Mol Cell Biol. 2005;25(1):136-146.

36. Kooistra MR, Dube N, Bos JL. Rap1: a key regulator in cell-cell junction formation. J Cell Sci. 2007;120(pt 1):17-22.

37. Pannekoek WJ, Kooistra MR, Zwartkruis FJ, Bos JL. Cell-cell junction formation: The role of Rap1 and Rap1 guanine nucleotide exchange factors. Biochim Biophys Acta. 2009;1788(4):790796.

38. Avraamides CJ, Garmy-Susini B, Varner JA. Integrins in angiogenesis and lymphangiogenesis. Nat Rev Cancer. 2008;8(8):604-617.

39. Gratton JP, Lin MI, Yu J, et al. Selective inhibition of tumor microvascular permeability by cavtratin blocks tumor progression in mice. Cancer Cell. 2003;4(1):31-39.

40. Satchi-Fainaro R, Mamluk R, Wang L, et al. Inhibition of vessel permeability by TNP-470 and its polymer conjugate, caplostatin. Cancer Cell. 2005;7(3):251-261.

41. Strilić B, Kucera T, Eglinger J, et al. The molecular basis of vascular lumen formation in the developing mouse aorta. Dev Cell. 2009;17(4):505-515.

42. Augustin HG, Koh GY, Thurston G, Alitalo K. Control of vascular morphogenesis and homeostasis through the angiopoietin-Tie system. Nat Rev Mol Cell Biol. 2009;10(3):165-177.

43. Fiedler U, Scharpfenecker M, Koidl S, et al. The Tie-2 ligand angiopoietin-2 is stored in and rapidly released upon stimulation from endothelial cell Weibel-Palade bodies. Blood. 2004;103(11): 4150-4156.

44. Greenberg JI, Shields DJ, Barillas SG, et al. A role for VEGF as a negative regulator of pericyte function and vessel maturation. Nature. 2008;456(7223):809-813.

45. Jain RK. Normalization of tumor vasculature: an emerging concept in antiangiogenic therapy. Science. 2005;307(5706):58-62.

46. Jacobson JR, Garcia JG. Novel therapies for microvascular permeability in sepsis. Curr Drug Targets. 2007;8(4):509-514.

47. Rigau V, Morin M, Rousset MC, et al. Angiogenesis is associated with blood-brain barrier permeability in temporal lobe epilepsy. Brain. 2007; 130(pt 7):1942-1956. 